\title{
Sustainability by Converting Waste Polyurethane Foam into Superior Polyurethane Urea Coatings
}

\author{
Ajay Vasudeo Rane ${ }^{*}$, Mukesh Kathalewar1, Vandana Jamdar1, V. K .Abitha², \\ Anagha Sabnis ${ }^{1}$ \\ ${ }^{1}$ Department of Polymer and Surface Engineering, Centre of Excellence and Elite Status-Government of Ma- \\ harashtra Centre for Green Technology, Institute of Chemical Technology (Formerly known as UDCT Mumbai), \\ Mumbai, India \\ ${ }^{2}$ Department of Polymer Science and Rubber Technology, Cochin University of Science and Technology, \\ Kerala, India \\ Email: ajayrane2008@gmail.com
}

Received 10 April 2015; accepted 25 April 2015; published 8 May 2015

Copyright (C) 2015 by authors and OALib.

This work is licensed under the Creative Commons Attribution International License (CC BY). http://creativecommons.org/licenses/by/4.0/

(c) (i) Open Access

\begin{abstract}
Recycling is a crucial area of research in Green Polymer Chemistry and developments in recycling are driven by environmental concerns, interests in sustainability and desire to decrease dependence on petroleum based materials. Sustainability refers to the development that meets the needs of present without comprising the ability of future generations. Polyurethane foams (PU) are widely used due to their light weight and superior heat insulation as well as good mechanical properties. However, large quantities of polyurethane foam are discharged during manufacturing/ processing as a waste and hence recycling of PU foam is necessary. In present study polyurethane foam is reacted with an alkanolamines in presence of a catalystin conventional as well as microwave method, but microwaves proved to be fast to depolymerise polyurethanes foam as compared to conventional method. The rate of reaction could be made identified by comparing the hydroxyl values of the two systems. The hydroxyl value increases as the time and microwave power increases. Further the depolymerised product with specified hydroxyl and amine groups is further cured with isocyanates for coating application and the coating formed is evaluated for physical, mechanical and chemical tests.
\end{abstract}

\section{Keywords}

Polyurethane Foam, Recycled Polyol, Isocyanates, Coatings

Subject Areas: Environmental Chemistry, High Polymer Chemistry

How to cite this paper: Rane, A.V., Kathalewar, M., Jamdar, V., Abitha, V.K. and Sabnis, A. (2015) Sustainability by Converting Waste Polyurethane Foam into Superior Polyurethane Urea Coatings. Open Access Library Journal, 2: e1533. 


\section{Introduction}

Polyurethanes are one of the most versatile polymers. They are synthesized by a polyaddition process of polyisocyanate and polyalcohol. Even though they are named after the characteristics urethane group, other moieties like ether or ester groups and links like urea, biurets or isocyanates can be present. In a wide variety of applications in consumer and industrial goods, the broad ranges of properties that can be tailored according to the need of the user ensure a sustainable utilization. There is no universally accepted definition of sustainability, but in its most widely acceptable meanings, it is a "sustainable development that meets the needs of present without compromising the ability of future generations to meet their own needs. It demands the reconciliation of environmental, social and economic demands" [1]. The main properties of polyurethanes are their high strength and abrasion resistance and inertness against oxygen and ozone. Most of the polyurethanes produced are used in formulation of rigid/flexible foam and elastomers with a wide variety of applications as adhesives, coatings, and insulating agents, etc. Foams are obtained by blowing air through the polymer or by adding water which reacts with residual isocyanate groups. The degree of rigidity of the resulting polymer can be controlled by changing the groups which may contain additional hydroxyl groups leading to a crosslinked polymer matrix. Polyurethane foams are extensively used in the automotive industry due to their contribution to the improvements in comfort part integration and weight reduction of vehicles. With regard to chemical recycling of polyurethanes two aspects must be highlighted. Polyurethane are used to manufacture durable goods, which means that it takes several years for these items to be disposed of into the solid waste stream. Moreover polyurethanes contain around $4 \mathrm{wt} \%$ of Nitrogen, which may hinder their recycling by oxidative treatments such as incineration or gasification due to the potential release of significant amounts of $\mathrm{NO}_{\mathrm{x}}$ in the gaseous effluents [1].

Solid polymeric materials undergo both physical and chemical changes when heat is applied usually resulting in undesirable changes in the properties of the material. A clear distinction needs to be made between thermal decomposition and thermal degradation. The American Society for Testing and Materials defines thermal decomposition as "A process of extensive change in chemical species caused by heat" and thermal degradation is "A process whereby the action of heat or elevated temperature on a material, product or assembly causes a loss of physical, mechanical or electrical properties" [2]. The most important chemolysis methods so far developed to reverse the polyurethane polymerization reaction are glycolysis and hydrolysis which are widely investigated but the process of aminolysis is less widely investigated. Polyurethane chemolysis by reaction with amines has been described in the literature. Watando has proposed a process based on polyurethane foam decomposition using Diethanolamine in an extruder and the resulting decomposed product could be used as an alternative virgin polyol in reclaiming polyurethane elastomers [3]. In an experiment by Fukaya, a reheating process for the products in the chemical recycling of rigid polyurethane foam by an extruder with diethanolamine as a decomposing agent was effective for improving the product stability [4]. In another experiment by Chuayjuljit rigid polyurethane foam scrap was depolymerised by aminolysis using diethylene triamine as a degrading agent and sodium hydroxide as both a reactant and catalyst, resulting in 4,4'-methylenedianiline [5]. Kanaya proposed a system wherein flexible foams were decomposed by alkanolamines without a catalyst at $150^{\circ} \mathrm{C}$ and decomposed products were completely separated into two layers, the upper liquid layer being a polyol and the lower liquid layer of methylene diphenyl amine [6]. Lee et al. carried out aminolysis of rigid polyurethane using diethylene triamine and studied the application of aminolysed products as hardeners of epoxy resins [7]. Sheratte initiated a process based on polyurethane decomposition by various agents. Several examples were provided for degradation with ethanolamine $\left(120^{\circ} \mathrm{C}\right)$, ammonia and ammonium hydroxide $\left(180^{\circ} \mathrm{C}\right)$, diethylene triamine $\left(200^{\circ} \mathrm{C}\right)$ and other basic reagents [8]. In all cases the process involved simultaneous or subsequent reaction with propylene oxide which allowed the different amines obtained to be quantitatively converted into polyols. The polyols derived from this process were used in the reformulation of new polyurethanes by polymerization with corresponding isocyanate and were suitable for application in rigid foams. In the present study, Diethanolamine (DEA) was used as a destroying agent in optimized ratio of 1:1 and 1:2 (PU foam: DEA) w/w and the reaction was carried out at $120^{\circ} \mathrm{C}$ for 10 hours in presence of $0.2 \% \mathrm{NaOH}$ on weight basis of PU foam as a transesterification catalyst in conventional method. Later to overcome the drawbacks of longer reaction times in conventional method, microwave studies with varying time and microwave power was done, which reduced reaction time from 10 hours to 30minutes and was beneficial for depolymerization reaction. The aminolysed product was characterized for hydroxyl and amine value by conventional methods of ASTM D1957 and ASTM D2073. Depolymerised product with hydroxyl and amine groups was successfully cured with isocyanate curing agents. The coated films were evaluated for physical, mechanical and chemical properties.

\footnotetext{
*Corresponding author.
} 


\section{Materials and Methods}

\subsection{Materials}

PU foam waste obtained from Hamilton India Pvt Ltd. was grinded and converted into small pieces. Diethanol amine and sodium hydroxide were of analytical reagent grade procured from SD Fine Chemicals Ltd., Mumbai. Isocyanates cross linkers were obtained from Bayer Material Science Ltd.

\subsection{Aminolysis of Polyurethanes (Conventional Method)}

Calculated quantities of PU foam, DEA and $\mathrm{NaOH}$ were charged in a four neck glass reactor equipped with stirrer, reflux condenser, temperature indicator and nitrogen inlet (see Table 1). PU foam and DEA were reacted in 1:1 (PUDE C1) and 1:2 (PUDE C2) (w/w) ratios along with 0.2\% NaOH catalyst on weight basis of PU foam. The aminolysis reaction was carried out at $180^{\circ} \mathrm{C}$ under reflux and nitrogen atmosphere for 10 hours. The depolymerised product was characterized by hydroxyl value, amine value and ATR analysis.

\subsection{Aminolysis of Polyurethanes (Microwave Method)}

In case of DEA, the steric hindrance at the hydrogen bond may contribute to weakening the association between the amino group of DEA and the carbonyl group of urethane. The weakness of the association between DEA and carbonyl may partially cause the hydrogen bond between the amino group of DEA and the ether of the urethane group, which will produce the Isocyanate/DEA urea adduct in the polyurethane foam decomposition process [6]. Due to longer reaction times taken by DEA, microwave radiations as a source of energy was chosen. The reaction time was reduced from 10 hours to $30 \mathrm{~min}$. In order to study the effect of various parameters in microwave, variation in reaction time and microwave power were carried out and the depolymerised product was characterized for hydroxyl and amine value to study the reaction mechanism. The details of the reactions carried out are tabulated (see Table 2 and Table 3 )

\subsection{Preparation of Polyurethane Urea Coatings}

Depolymerised product with hydroxyl value $315 \mathrm{mgKOH} / \mathrm{g}$ and amine value $22 \mathrm{mgKOH} / \mathrm{g}$ prepared in the above steps was cured with Hexamethylene diisocyanate [HDI biuret], Isophorone diisocyanate [IPDI] curing agent. Xylene: $\operatorname{MEK}(70: 30 \mathrm{v} / \mathrm{v})$ mixture was used as solvent. The films were applied on mild steel panels $(150 \mathrm{~mm} \times$

Table 1. Conventional Batch of DEA/PU foam.

\begin{tabular}{ccc}
\hline BATCH & PUDE C1 & PUDEC2 \\
\hline PU Foam (g) & 20 & $\mathbf{2 0}$ \\
DEA (g) & 20 & $\mathbf{4 0}$ \\
NaOH (g) & $\mathbf{0 . 0 4}$ & $\mathbf{0 . 0 4}$ \\
\end{tabular}

PU-Polyurethane Foam/DE-Diethanol Amine/C-Conventional.

Table 2. Microwave assisted depolymerization using DEA varying in reaction time.

\begin{tabular}{|c|c|c|c|}
\hline BATCH & PUDE T1 & PUDE T2 & PUDE T3 \\
\hline PU Foam (g) & 10 & 10 & 10 \\
\hline DEA (g) & 20 & 20 & 20 \\
\hline NaOH (g) & 0.02 & 0.02 & 0.02 \\
\hline Time (min) & 10 & 20 & 30 \\
\hline \multicolumn{4}{|c|}{$@ 180^{\circ} \mathrm{C}$ at $400 \mathrm{~kW}$} \\
\hline
\end{tabular}

PU-Polyurethane Foam/DE-Diethanol Amine/T-Reaction with different times 
Table 3. Microwave assisted depolymerization using DEA varying in microwave power.

\begin{tabular}{cccc}
\hline BATCH & PUDE M1 & PUDE M2 & PUDE M3 \\
\hline PU Foam (g) & 10 & 10 & 10 \\
DEA (g) & 20 & 20 & 20 \\
NaOH (g) & 0.02 & 0.02 & 0.02 \\
Microwave Power (kW) & 400 & $\mathbf{6 0 0}$ & $\mathbf{8 0 0}$ \\
\hline
\end{tabular}

PU-Polyurethane Foam/DE-Diethanol Amine/M-Reaction with different microwave power.

$100 \mathrm{~mm} \times 0.5 \mathrm{~mm}$ ) and cured at $120^{\circ} \mathrm{C}$ for 30 minutes. The coatings were further evaluated for mechanical and chemical properties.

\section{Results and Discussion}

Here we have used DEA as a destroying agent in order to depolymerise PU foam. The conventional method took 10 hours at a temperature of $180^{\circ} \mathrm{C}$. The confirmation of depolymerization was done on the basis of hydroxyl and amine values of the depolymerised product (see Table 4).

\subsection{Hydroxyl Value/Amine Value}

From the tabulated results (see Table 4), we observe that hydroxyl value increased as the amount of DEA increased. This is due to the fact that DEA solvolyses the urethane bond and disintegrates the polymeric network into mixture of smaller molecular weight oligomers and monomers. Amine value also showed an increase with the increase in the quantity of DEA in the depolymerisation reaction. This must be due to the generation of amine simultaneously along with the formation of hydroxyl moiety, as side reactions in the depolymerisation reactions. Further the effect of time and microwave power on the depolymerization reaction of PU foam was also studied (see Table 5). The conventional method takes long hours, i.e. 10hours for depolymerization reaction and also side reactions take place which leads amine formations and further requires purification steps to remove excess amines which involves energy and cost.

Thus conventional method is not a sustainable method to be used.

Depolymerisation reaction when carried out conventionally with DEA takes long hours to depolymerise polyurethane foam, due to the fact that the stearic hindrance at the hydrogen bond may contribute to weakening the association between amino group of DEA and carbonyl group of urethane. Hence the depolymerization was also studied using the assistance of microwave with varying time and varying microwave power. Microwave heating is based on the ability of a particular substance such as a solvent or substrate to absorb microwave energy and effectively convert the electromagnetic energy to heat energy. Molecules with dipole moment attempt to align themselves with the oscillating electric field of the microwave irradiation leading to rotation and hence microwave reduces the stearic hindrance and hence the reaction time reduces.

From the above mentioned results in Table 5, we can observe that there is an increase in the hydroxyl value which is due to the disintegration of the PU foam into low molecular weight fractions as well as monomers, which contributes to the increase in hydroxyl value as time increases from $10 \mathrm{~min}$ to $30 \mathrm{~min}$. Amine value also increased, but it may be observed that there was an decrease in the amine value when compared with the conventional method. This proved that there were less side reactions taking place in microwave reactor which can be beneficial to use depolymerised product without further purification.

When microwave power was increased from $400 \mathrm{~kW}$ to $600 \mathrm{~kW}$ to $800 \mathrm{~kW}$, we observed that there was an increase in hydroxyl as well as amine value, due to formation of low molecular weight hydroxyl species along with amine moieties due to increase in internal energy of the reaction mixture by absorption of the microwave energy at different microwave power (see Table 6).

\subsection{Spectroscopic Analysis}

ATR spectra in Figure 1, for depolymerised product using DEA, shows a transmission band at $3400 \mathrm{~cm}^{-1}$, 
Table 4. Hydroxyl value and amine value of conventional batch using DEA.

\begin{tabular}{ccc}
\hline Batch no & PUDE C1 & PUDE C2 \\
\hline Hydroxyl Value $(\mathrm{mgKOH} / \mathrm{g})$ & $\mathbf{3 2 0}$ & $\mathbf{4 4 0}$ \\
Amine Value $(\mathrm{mgKOH} / \mathrm{g})$ & $\mathbf{9 0}$ & $\mathbf{1 1 0}$ \\
\hline
\end{tabular}

PU-Polyurethane Foam/DE-Diethanol Amine/C-Conventional.

Table 5. Hydroxyl \& amine value of microwave assisted aminolysis (varying time) using DEA.

\begin{tabular}{cccc}
\hline Batch no & PUDE T1 & PUDE T2 & PUDE T3 \\
\hline Hydroxyl Value $(\mathrm{mgKOH} / \mathrm{g})$ & $\mathbf{2 5 0}$ & $\mathbf{3 0 6}$ & $\mathbf{3 1 5}$ \\
Amine Value $(\mathrm{mgKOH} / \mathrm{g})$ & $\mathbf{2 0}$ & $\mathbf{2 1}$ & $\mathbf{2 2}$ \\
\hline
\end{tabular}

PU-Polyurethane Foam/DE-Diethanol Amine/T-Reaction with different times.

Table 6. Hydroxyl \& amine value of microwave assisted aminolysis (varying power) using DEA.

\begin{tabular}{cccc}
\hline Batch no & PUDE M1 & PUDE M2 & PUDE M3 \\
\hline Hydroxyl Value (mgKOH/g) & $\mathbf{3 1 5}$ & $\mathbf{3 3 5}$ & $\mathbf{2 3}$ \\
Amine Value (mgKOH/g) & $\mathbf{2 2}$ & $\mathbf{2 4}$ \\
\hline
\end{tabular}

PU-Polyurethane Foam/DE-Diethanol Amine/T-Reaction with different microwave power.

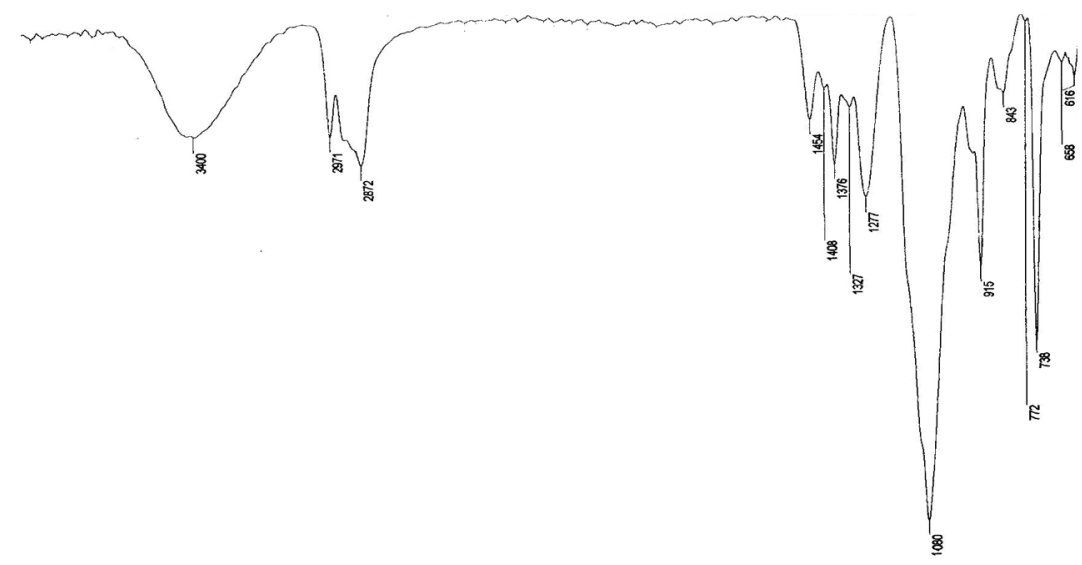

Figure 1. ATR spectra of aminolysed product using DEA.

which indicates the $\mathrm{OH}$ stretch in the recycled polyol. The peaks at $2971 \mathrm{~cm}^{-1}$ and $2872 \mathrm{~cm}^{-1}$ represent the stretching vibrations of $\mathrm{CH}$ bonds in aliphatic carbons. Bending vibrations of methylene group appear in recycled polyol chain at $1376 \mathrm{~cm}^{-1}$ and $1454 \mathrm{~cm}^{-1}$. Bending vibrations of NH group in amines appear in 1602 $\mathrm{cm}^{-1}$ and $1649 \mathrm{~cm}^{-1}$. The absorption band at $1080 \mathrm{~cm}^{-1}$ and $1277 \mathrm{~cm}^{-1}$ are related to aliphatic ether group of recycled polyol. The peak at $1327 \mathrm{~cm}^{-1}$ confirms the presence of aromatic amines in the depolymerised product. The peak at $1408 \mathrm{~cm}^{-1}$ confirms the $\mathrm{C}-\mathrm{C}$ in aromatic rings. Also the peaks at $616 \mathrm{~cm}^{-1}, 658 \mathrm{~cm}^{-1}$ indicate the $\mathrm{CH}$ bend. $\mathrm{C}-\mathrm{H}$ in aromatic rings is confirmed by the presence of peaks at $738 \mathrm{~cm}^{-1}, 772 \mathrm{~cm}^{-1}$ and $843 \mathrm{~cm}^{-1}$.

ATR spectra in the above Figure 2 confirmed the formation of polyurethane urea coating, the presence of peak at $3336 \mathrm{~cm}^{-1}$ confirmed the NH stretch in urea. The peak at $1725 \mathrm{~cm}^{-1}$ confirmed the presence of $\mathrm{C}=\mathrm{O}$ in urethane. $\mathrm{NH}$ bends were confirmed by the presence of transmission bands at $1597 \mathrm{~cm}^{-1}$ and $1528 \mathrm{~cm}^{-1}$. The peaks at $1310 \mathrm{~cm}^{-1}, 1219 \mathrm{~cm}^{-1}, 1164 \mathrm{~cm}^{-1}$ and $1066 \mathrm{~cm}^{-1}$ confirmed the $\mathrm{C}-\mathrm{O}$ stretch in ether. The NH wag was observed at $850 \mathrm{~cm}^{-1}$. The peaks at $1463 \mathrm{~cm}^{-1}$ and $1413 \mathrm{~cm}^{-1}$ represent the $\mathrm{C}-\mathrm{C}$ stretch in aromatic ring, while peak at $815 \mathrm{~cm}^{-1}$ and $769 \mathrm{~cm}^{-1}$ represent the $\mathrm{CH}$ in aromatic rings. The transmission band $685 \mathrm{~cm}^{-1}$ and 585 $\mathrm{cm}^{-1}$ confirmed the $\mathrm{CH}$ bend. 


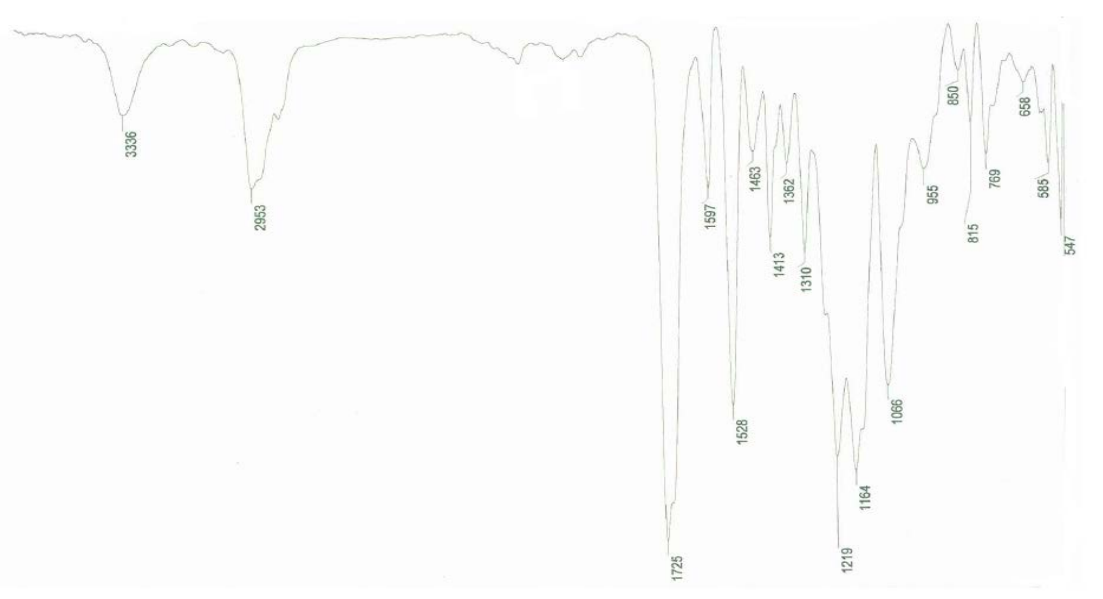

Figure 2. ATR spectra of polyurethane urea coating.

\subsection{Properties of Polyurethane Urea Coatings}

The coatings were applied using Xylene: MEK in ratio $70: 30 \mathrm{w} / \mathrm{w}$ and cured at $120^{\circ} \mathrm{C}$. A digital electromagnetic thickness gauge instrument was used to measure the dry film thickness (DFT) of each coated panel and all the films were of dry film thickness in the range of 60 - 80 microns. Each coating showed gloss which can be attributed to structure of raw materials used in preparation of coatings. Gloss of film is related to the polyether linkages of the polyol, urethane linkages due to which orderliness was incorporated across polymer backbone. Presence of oxygen in ether linkages could be the reason for inter-chain locking because of dipole interactions. This offers regularity in packing of chains and so does the crystallinity. Pencil Hardness of the film is equated with the pencil that just fails to damage the coating and Scratch hardness of the film is equated with the load at which needle penetrates the coating. Pencil Hardness and Scratch hardness of IPDI based coatings showed consent result. This is due to the fact that presence of polyurethane linkages in the film makes them tough and also difficult to notch off. Impact is the momentary shock which could be sustained if the energy of impact would be dissipated uniformly over the coating. For this free volume between the chains play a crucial role. Impact resistance was satisfactory. Each of the film could pass the impact test (both on surface of coating and reverse) when indenter was released from the height of $60 \mathrm{~cm}$. This could be due to aliphatic nature of the film formed across the polymer backbone, with free volume available between adjacent chains. The adhesion of the coatings to the metal substrate was investigated by crosshatch method. It was observed that all the coatings showed excellent adhesion. This could be due to the polar nature of the polymer backbone containing urethane moieties in IPDI based coatings. The flexibility of the coated panels was evaluated using Conical Mandrel Bending test. It was observed that the coatings exhibited excellent flexibility. This could be due to the aliphatic nature of Polyether polyol and IPDI which increases the flexibility of final coating.

Acid and Alkali resistance were investigated according to ASTM D1308. Coatings showed excellent acid resistance, wherein no visible damage was done to any of the films kept in acid solution for 24 hours. In alkali solution slight loss of gloss was observed for IPDI coatings and minute cracks were observed on HDI-biuret based coatings. The excellent chemical resistance could be due to the presence of intermolecular hydrogen bonding in the cross-linked polymeric structure which helps in shielding the acid susceptible hydroxyl group resulting in very good acid resistance. The solvent resistance of coatings was evaluated by MEK and Xylene rub method to study the effect of polar and non-polar solvent rub on the coating properties. The coated films showed excellent solvent resistance even after 200 double rubs of Xylene. This could be due to highly cross-linked, dense and polar polymeric films which are highly adherent to the metal substrates. The polar nature of the polymeric film could be the reason for poor resistance to MEK, i.e. 110 - 120 MEK double rubs (see Table 7).

\section{Conclusion}

Aminolysis of waste PU foam was successfully carried out to generate oligomers having hydroxyl and amine functionality. Formation of polyurethane urea coating attaining satisfactory properties showed that aminolysed 
Table 7. Mechanical and chemical properties of polyurethane urea coatings.

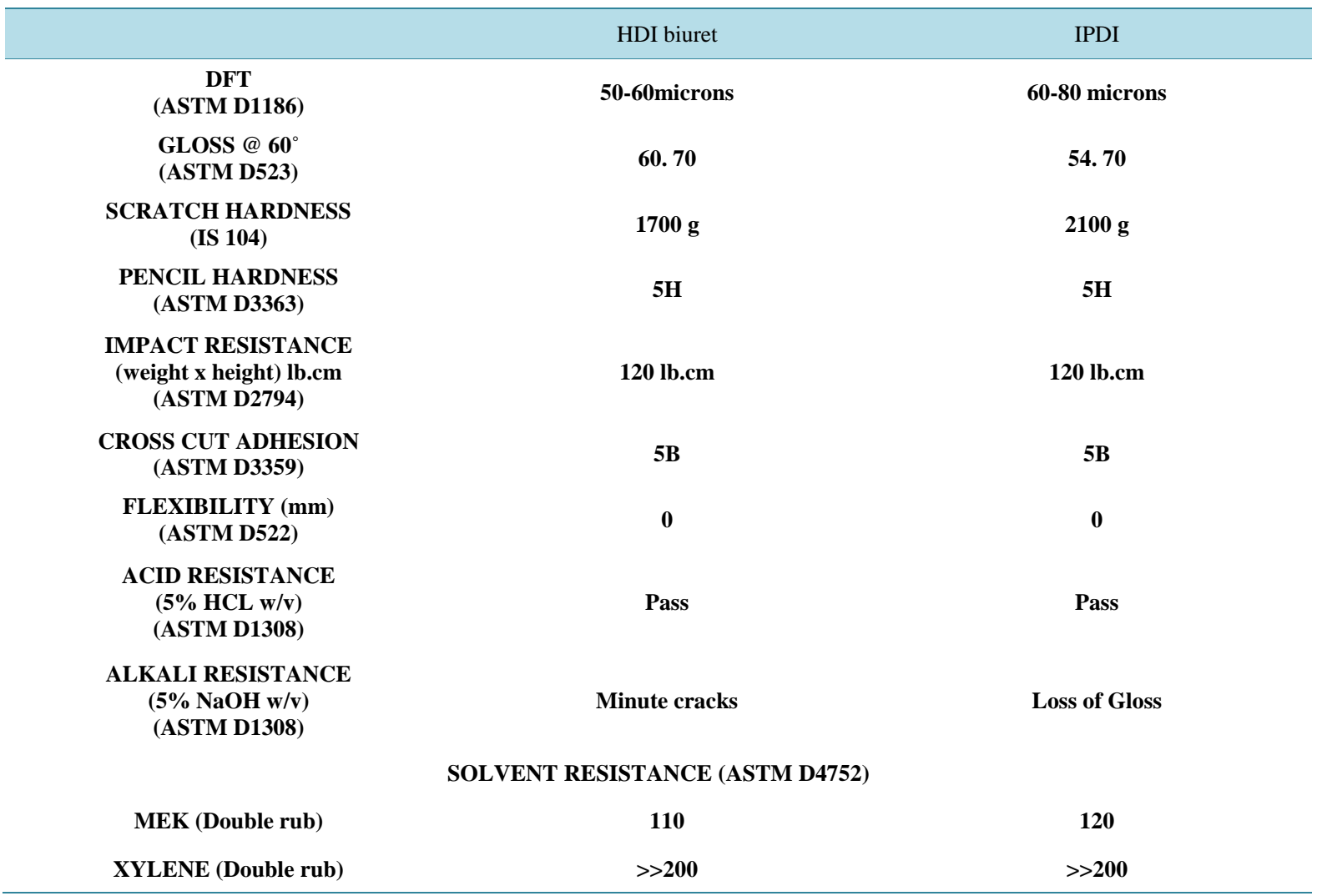

product synthesized from waste PU foam could be a successful replacement for virgin polyols. Measured values of mechanical and chemical properties confirmed that the polyurethane urea based coatings exhibited overall good performance properties. Microwave assisted aminolysis proved to be advantageous over conventional method considering the time and energy required for depolymerisation reaction. The study mentioned here is a sustainable way to utilize waste PU foam in coating applications and may contribute to a green environment by reducing PU foam waste to a considerable amount.

\section{Acknowledgements}

Authors would like to thank Mr Rakesh Jain of Hamilton House Pvt Ltd., India for providing us with waste polyurethane samples. We also express our sincere thanks to Dr. K. Rajkumar, Dr P. Thavamani and Mr Nimish of IRMRA, for helping in carrying out the ATR analysis.

\section{References}

[1] Avar, G., Meier-Westhues, U., Casselmann, H. and Achten, D. (2012) Polyurethanes. Germany Bayer Material Science AG, Leverkusen, 411- 441.

[2] Beyler, C.L. and Hirschler, M.M. (2002) Thermal Decomposition of Polymers. SFPE Handbook of Fire Protection Engineering 2, Section 1, Chapter 7, 111-131.

[3] Watando, H., Saya, S., Fukaya, T., Fujieda, S. and Yamamoto, M. (2006) Improving Chemical Recycling Rate by Reclaiming Polyurethane Elastomer from Polyurethane Foam. Polymer Degradation and Stability, 91, 3354-3359. http://dx.doi.org/10.1016/j.polymdegradstab.2006.05.017

[4] Fukaya, T., Watando, H., Fujieda, S., Saya, S., Thai, C.M. and Yamamoto, M. (2006) Reheating Decomposition Process as Chemical Recycling for Rigid Polyurethane Foam. Polymer Degradation and Stability, 91, 2549-2553. http://dx.doi.org/10.1016/j.polymdegradstab.2006.05.011

[5] Chuayjuljit, S., Norakankorn, C. and Pimpan, V. (2002) Chemical Recycling of Rigid Polyurethane Foam Scrap via Base Catalyzed Aminolysis. Journal of Metals, Materials and Minerals, 12, 19-22. 
[6] Kanaya, K. and Takahashi, S. (1994) Decomposition of Polyurethanes Foam by Alkanolamines. Journal of Applied Polymer Science, 51, 675-682. http://dx.doi.org/10.1002/app.1994.070510412

[7] Lee, D.S., Kim, B. and Hyun, S.W. (2001) Curing Behavior of Epoxy Resins Using Aminolysis Products of Waste Polyurethanes as Hardners. Journal of Engineering Industrial Chemistry, 7, 449-453.

[8] Aguado, J. and Serrano, D. (1999) Feed Stock Recycling of Plastic Waste, Chapter 2. The Royal Society of Chemistry, London. 